\title{
Investigation on Quality of Life and Its Influencing Factors in Young Cancer Patients
}

\author{
Shuzhi Xue*, Baohua Cao, Xixia Liu \\ Department of Oncology, Shaanxi Provincial People’s Hospital, China.
}

How to cite this paper: Shuzhi Xue, Baohua Cao, Xixia Liu. (2021) Investigation on Quality of Life and Its Influencing Factors in Young Cancer Patients. International Journal of Clinical and Experimental Medicine Research, 5(2), 208-213.

DOI: 10.26855/ijcemr.2021.04.015

Received: March 12, 2021

Accepted: April 6, 2021

Published: April 21, 2021

*Corresponding author: Shuzhi Xue, Department of Oncology, Shaanxi Provincial People's Hospital, China. Email: 5945116@qq.com

\begin{abstract}
Objective: To provide reference for improving the quality of life of young cancer patients and implementing targeted and effective intervention measures by investigating and analyzing the current situation of quality of life of young cancer patients and its influencing factors. Methods: The convenience sampling method was used to investigate and analyze 155 young cancer patients from four large Grade A hospitals in Xi'an, Shaanxi Province, using questionnaires such as the general condition questionnaire, Herth hope index scale HHI, social support scale, and CARE-SF. Results: The total score of quality of life of young cancer patients was $(34.38 \pm 17.16)$, the total score was low, indicating that young cancer patients had relatively good quality of life experience. Among them, the most influential factors were course of disease, followed by marriage, childbirth and age. At the same time, the quality of life of young cancer patients is correlated with the level of hope and social support. Conclusion: The quality of life of young cancer patients is affected by many factors. We should pay more attention to this special group in our clinical practice.
\end{abstract}

\section{Keywords}

Young Cancer Patients, Level of Hope, Social support, the Quality of Life

Cancer is a common cause of death among Adolescents and Young Adults (Ayas). Every year around the world, nearly one million Ayas are diagnosed with cancer [1], accounting for nearly $40 \%$ of the total cause of death [2-3]. The International Institute for Research on Cancer (IARC) defines young cancer patients as those aged 15-39 years who are diagnosed with cancer [4]. 15-39 years old in the prime period of life, economic foundation, social foundation and family marriage foundation is not yet solid, shoulder the study, work, marriage, career development and other important responsibilities. Illness forces them to change their lives as their social role shifts from caregiver to caretaker. Compared with their healthy peers, young cancer patients have poor physical condition, low role adaptation ability, cognitive or emotional disorders, low social function and other problems, and a higher incidence of chronic diseases and disabilities [5]. Modern oncology has basically reached a consensus that the quality of life of cancer patients can better represent the curative effect and recovery of patients than the survival period and case fatality rate [6]. Therefore, the improvement of life quality is regarded as an important evaluation index of clinical treatment effect. In order to provide theoretical and practical basis for improving the quality of life of young cancer patients in Shaanxi Province, this paper aims to investigate the quality of life of young cancer patients and its influencing factors.

\section{Subjects and methods}

\subsection{Subjects}

The convenience sampling method was used to select the patients who were initially diagnosed by pathology as 
malignant tumor with a disease course of more than 3 months from the relevant tumor departments (Oncology Surgery Department, Oncology Medicine Department, General Surgery Department, Gynecology Department, Hematology Department, etc.) of four large Grade III Class A hospitals in Xi’an from May, 2019 to May, 2020. Aged 15-39, a total of 165 patients were able to cooperate in completing the questionnaire. Effective questionnaires were collected in 155 cases with effective recovery of 93.94\%. The youngest, oldest and median age were 15 years old, 39 years old, and 35 years old. There were 78 males and 77 females. There were 25 cases of breast cancer, 21 cases of colorectal cancer, 16 cases of stomach cancer, 15 cases of lung cancer, 13 cases of cervical cancer, 10 cases of ovarian cancer, 15 cases of leukemia/lymphoma/myeloma, 8 cases of liver cancer, 7 cases of melanoma, 10 cases of thyroid cancer, 5 cases of esophageal cancer, 4 cases of osteosarcoma, 5 cases of pancreatic cancer, and 1 case of vulvar cancer.

\subsection{Method}

\subsubsection{Assessment tools}

(1) The general information questionnaire includes: gender, age, education level, occupation, personality, religious belief, marital status, fertility and other demographic data; sociological data such as family per capita monthly income, payment method and primary caregivers; the duration of diagnosis, the treatment and the cognition of the disease are the three parts related to the patient's disease.

(2) Herth Hope Index Scale (HHI) [7], a total of 12 items, including three factors: positive attitude towards the present and future, positive actions taken, and maintaining close relationship with others. From strongly disagree, disagree, agree and strongly agree, 4-scale scoring method is adopted, with a total score of 12 to 48 points. The higher the score is, the higher the level of hope is, among which 316 is entitled reverse scoring. This scale was translated and introduced into China by Zhao Haiping from China Medical University. The Cronbach's coefficient of this scale was only 0.87 . The retest reliability is 0.90 [8].

(3) Social support scale (SSRS) [9], containing 10 items, including three dimensions of objective support, subjective support and utilization of social support. The total score is the sum of the scores of the ten items. Normal: total score $\geq 20$ points. The higher the score, the higher the degree of social support. The total score is less than 20 , indicating less social support. The 20-30 degree of social support is average, and the 30-40 degree of social support is satisfactory.

(4) Quality of life: CARES-SF [10], a scale developed by Schag, Ganz \& Heinrich in 1991 to evaluate the quality of life of cancer patients. There were 34 items in the scale, including 5 dimensions, including physiology, psychosocial, relationship with medical staff, marital relationship, and sexual function. Each item was rated on 5 levels, with 0 = none, 1 = mild, 2 = moderate, 3 = heavy, 4 = severe; the total score of the scale is $0-136$, and the higher the score, the more serious the problems and the worse the quality of life of the patients.

\subsubsection{Statistical methods}

SPSS21.0 software was used for statistical analysis. Measurement data were described as mean \pm standard deviation (' $\mathrm{x} \pm \mathrm{s}$ ), and enumeration data were described as percentage (\%). Pearson correlation analysis and multiple stratified regression analysis were performed on the data. $\mathrm{P} \leq 0.05$ was considered to be statistically significant.

\section{The Results}

\subsection{Overall situation of cancer rehabilitation evaluation of young cancer patients}

The total recovery score of young cancer patients was (34.38 \pm 17.16$)$, which was at a low level, indicating that young cancer patients had relatively good life experience. Those under 35 years old, unmarried, less course of disease and less treatment plan had better quality of life experience; the higher income, the unmarried, and the less course of disease and treatment plan had better psychosocial adaptability. People under 35 years old and having fewer children have a lower impact on marriage; men, those under 35 years of age and those who had fewer children had a lower impact on sexual function. And there was statistical difference among all groups (see Table 1).

\subsection{Multiple regression analysis results affecting the total score of cancer rehabilitation evaluation}

The regression model of total score of cancer rehabilitation quality evaluation showed statistical significance ( $\mathrm{F}$ $=3.257, \mathrm{P}<0.05$ ), and its correction coefficient $\mathrm{R} 2=0.093$, indicating that the variation caused by repurchase accounted for $9.3 \%$ of the total variation. The most influential factor was the course of disease $(\beta=0.170, \mathrm{P}<0.05)$, which was statistically significant, followed by marriage, childbirth, age, etc. (see Table 2). 
Table 1. Sociodemographic characteristics, disease status and cancer rehabilitation evaluation scores of patients

\begin{tabular}{|c|c|c|c|c|c|c|c|c|c|}
\hline Project & Number & $\begin{array}{l}\text { CSF total } \\
\text { score }\end{array}$ & $\begin{array}{l}\text { p val- } \\
\text { ue }\end{array}$ & $\begin{array}{c}\text { Psycho- } \\
\text { Social }\end{array}$ & $\begin{array}{l}\text { p val- } \\
\text { ue }\end{array}$ & $\begin{array}{c}\text { Marital } \\
\text { relations }\end{array}$ & $\mathrm{p}$ value & $\begin{array}{c}\text { Sexual } \\
\text { function }\end{array}$ & $\begin{array}{c}\mathrm{p} \\
\text { value }\end{array}$ \\
\hline Sex & & & 0.236 & & 0.418 & & 0.258 & & 0.033 \\
\hline Male & 80 & $33.60 \pm 17.89$ & & $13.36 \pm 8.43$ & & $4.14 \pm 4.21$ & & $2.11 \pm 2.48$ & \\
\hline Female & 75 & $37.00 \pm 17.58$ & & $14.41 \pm 7.62$ & & $4.95 \pm 4.67$ & & $3.09 \pm 3.18$ & \\
\hline Age & & & 0.032 & & 0.717 & & 0.013 & & 0.001 \\
\hline$<35$ & 76 & $32.14 \pm 16.62$ & & $13.63 \pm 8.09$ & & $3.63 \pm 3.95$ & & $1.75 \pm 2.31$ & \\
\hline$>=35$ & 79 & $38.28 \pm 18.42$ & & $14.1 \pm 8.04$ & & $5.39 \pm 4.74$ & & $3.39 \pm 3.13$ & \\
\hline Laincome & & & 0.24 & & 0.049 & & 0.957 & & 0.722 \\
\hline$<3000$ & 74 & $38.70 \pm 18.56$ & & $15.50 \pm 9.15$ & & $4.59 \pm 4.54$ & & $2.39 \pm 2.64$ & \\
\hline $3000-5000$ & 52 & $33.10 \pm 17.38$ & & $12.17 \pm 9.30$ & & $4.56 \pm 4.56$ & & $2.75 \pm 3.10$ & \\
\hline$>=5000$ & 29 & $32.97 \pm 16.02$ & & $10.70 \pm 5.62$ & & $4.31 \pm 4.12$ & & $2.79 \pm 3.10$ & \\
\hline $\begin{array}{c}\text { Marital } \\
\text { status }\end{array}$ & & & 0.027 & & 0.006 & & 0.002 & & 0.001 \\
\hline Unmarried & 26 & $27.92 \pm 13.54$ & & $12.69 \pm 7.53$ & & $1.69 \pm 2.38$ & & $0.62 \pm 1.06$ & \\
\hline Married & 116 & $35.91 \pm 18.11$ & & $13.81 \pm 7.73$ & & $5.09 \pm 4.5$ & & $2.9 \pm 2.82$ & \\
\hline Other & 13 & $40.25 \pm 18.64$ & & $15.00 \pm 9.66$ & & $5.67 \pm 5.02$ & & $4.08 \pm 4.06$ & \\
\hline Fertility & & & 0.166 & & 0.739 & & 0.006 & & 0.005 \\
\hline a child & 77 & $33.54 \pm 16.05$ & & $13.29 \pm 8.09$ & & $4.06 \pm 3.73$ & & $2.45 \pm 2.9$ & \\
\hline $\begin{array}{l}2 \text { or more } \\
\text { childs }\end{array}$ & 60 & $38.40 \pm 20.07$ & & $14.47 \pm 8.18$ & & $5.78 \pm 5.06$ & & $3.28 \pm 2.93$ & \\
\hline nullipara & 18 & $31 \pm 16.30$ & & $14.11 \pm 8.20$ & & $2.33 \pm 3.99$ & & $0.83 \pm 1.51$ & \\
\hline Course & & & 0.01 & & 0.001 & & 0.141 & & 0.116 \\
\hline$<6$ months & 56 & $31.13 \pm 16.68$ & & $11.82 \pm 7.09$ & & $3.79 \pm 3.89$ & & $2.04 \pm 2.23$ & \\
\hline 6-12 months & 52 & $33.71 \pm 17.04$ & & $12.98 \pm 6.92$ & & $4.50 \pm 4.47$ & & $2.62 \pm 3.08$ & \\
\hline$>12$ months & 47 & $41.45 \pm 18.68$ & & $17.36 \pm 9.39$ & & $5.49 \pm 4.91$ & & $3.21 \pm 3.22$ & \\
\hline Treatment & & & 0.046 & & 0.013 & & 0.156 & & 0.815 \\
\hline $\begin{array}{l}\leq 2 \text { kinds of } \\
\text { schemes }\end{array}$ & 91 & $33.6 \pm 17.3$ & & $12.6 \pm 7.7$ & & $4.4 \pm 4.0$ & & $2.7 \pm 2.9$ & \\
\hline $\begin{array}{l}\text { >2kinds of } \\
\text { schemes }\end{array}$ & 64 & $41.4 \pm 20.5$ & & $17.0 \pm 9.8$ & & $5.8 \pm 5.2$ & & $2.8 \pm 3.3$ & \\
\hline
\end{tabular}

Table 2. Multiple regression analysis results affecting the total score of cancer rehabilitation evaluation

\begin{tabular}{cccccccc}
\hline Project & $\mathrm{B}$ & $\mathrm{S} . \mathrm{E}$ & $\beta$ & $\mathrm{t}$ & Adjust R $^{2}$ & $\mathrm{~F}$ & $\mathrm{P}$ \\
\hline Gender & 3.098 & 2.824 & 1.097 & 0.087 & & & \\
Age & 2.133 & 1.742 & 1.224 & 0.117 & & \\
Laincome & -2.309 & 1.901 & -1.215 & -0.099 & & 0.003 \\
Marital status & 5.588 & 3.507 & 1.593 & 0.162 & 0.093 & 3.257 & \\
Fertility & 4.072 & 2.261 & 1.801 & 0.157 & & \\
Course & 3.712 & 1.795 & 2.068 & 0.17 & & \\
Treatment & 2.896 & 2.823 & 1.026 & 0.085 & & \\
\hline
\end{tabular}

\section{3 level of cancer rehabilitation evaluation and hope, social support}

The correlation analysis of cancer rehabilitation evaluation scores and negatively correlated with social support 
in the utilization of degrees, psychosocial, and form the relationship between the medical staff, and hope to level the total score and hope positive action in horizontal dimension are negatively correlated, psychological and social dimensions of hope level of intimacy dimension and exploitation degree of social support are negatively correlated. The marital relationship dimension is positively correlated with the intimate relationship dimension of the level of hope. The neutral functional dimension of cancer rehabilitation evaluation was positively correlated with the objective support of social support (see Table 3).

Table 3. The relationship between the scores of cancer rehabilitation evaluation, the level of hope and the scores of social support scale $(\mathbf{n}=155)$

\begin{tabular}{ccccccccc}
\hline Project & $\begin{array}{c}\text { HHI } \\
\text { total } \\
\text { score }\end{array}$ & $\begin{array}{c}\text { Future } \\
\text { attitude }\end{array}$ & $\begin{array}{c}\text { Positive } \\
\text { action }\end{array}$ & $\begin{array}{c}\text { Intimate } \\
\text { relationship }\end{array}$ & $\begin{array}{c}\text { SSRS } \\
\text { total } \\
\text { score }\end{array}$ & $\begin{array}{c}\text { Objective } \\
\text { support }\end{array}$ & $\begin{array}{c}\text { Subjective } \\
\text { support }\end{array}$ & $\begin{array}{c}\text { Support } \\
\text { utilization }\end{array}$ \\
\hline CSF total score & -0.123 & -0.075 & -0.191 & -0.004 & 0.011 & 0.059 & 0.060 & $-0.213^{*}$ \\
physiological & -0.093 & -0.067 & -0.141 & 0.027 & 0.022 & 0.015 & 0.089 & -0.175 \\
$\begin{array}{c}\text { Psychosocial } \\
\text { Relationship between }\end{array}$ & $-0.213^{*}$ & -0.122 & $-0.288^{*}$ & -0.100 & -0.070 & -0.024 & -0.008 & $-0.232^{*}$ \\
$\begin{array}{c}\text { CSF and medical } \\
\text { personnel }\end{array}$ & $-0.199^{*}$ & -0.095 & $-0.202^{*}$ & $-0.202^{*}$ & 0.008 & 0.047 & 0.052 & -0.123 \\
$\begin{array}{c}\text { Marital relationship } \\
\text { Sexualfunction }\end{array}$ & 0.125 & 0.082 & 0.063 & $0.197^{*}$ & 0.109 & 0.101 & 0.146 & -0.122 \\
\hline * P $<0.05$ & 0.019 & -0.001 & -0.011 & 0.074 & 0.115 & $0.250^{*}$ & 0.032 & -0.024 \\
\hline
\end{tabular}

$* \mathrm{P}<0.05$

\section{Discuss}

\subsection{Studies show that the related factors affecting the quality of life of young cancer patients include gender, age, income, marriage, fertility, disease course and treatment plan}

Younger people, especially men, had less impact on quality of life than women. This suggests that women suffer more psychological and sexual stress during the disease than men. Hu Liping [11] believes that younger patients had better energy and social activities than older patients. Patients with better marital status had better quality of life than those who were divorced or bereaved. The general physical function and family social function of males were stronger than that of females, which indicated that males had better acceptance and cognition of tumor stress events and received more support. Liu Shaohua et al. [12] investigated the quality of life of 280 breast cancer patients receiving postoperative chemotherapy and analyzed the influencing factors and found that the younger the patients, the better the quality of life. The reason is that some young cancer patients are still dependent on their parents in terms of life independence, especially in terms of economy. Therefore, young cancer patients are less worried about life than middle-aged cancer patients. It is also common sense that as people get older, the more things they think about, the more stress they feel from all sides. The shorter the course of the disease, the earlier the tumor stage, and the simpler the treatment, the less impact on the quality of life of the patients.

\subsection{The total score of cancer rehabilitation evaluation was negatively correlated with the utilization de- gree of social support, indicating that the higher the utilization degree of social support, the higher the quality of life}

We should pay more attention to those who are pessimistic, unmarried and have fewer children. These patients are often self-closed, unwilling to use the social resources around them, which will form a vicious circle, not conducive to the recovery of the disease. Ke Qiujin et al. [13] showed that the overall quality of life of patients in the experimental group who received comprehensive social support (telephone follow-up, network support, on-site guidance, and social activities) was better than that of the control group.Tang Lei et al. [14] also believed that cancer not only needs drug treatment, but also needs the support of family and society, especially the support and encouragement of spouses, children and other immediate family members. Married people accounted for $89 \%$ in this study. Young cancer patients would become sensitive and suspicious in their marriage life due to the fear of disease recurrence and metastasis, and worried about the negative impact of the disease on their marriage relationship. Good communication is the basis for solving problems together, and the spouse is the main source of social support for patients. Effective communication between husband and wife can enable both parties to timely understand each 
other's feelings, reduce conflicts, release their inner pressure, and reduce the burden of disease [15-16].

\subsection{Psychosocial and relationship dimensions with medical personnel in the evaluation of cancer reha- bilitation are negatively correlated with the total score of hope level and the positive action dimension of hope level, among which psychosocial dimension is negatively correlated with the intimate relationship dimension of hope level and the utilization degree of social support}

It shows that the better the patient's psychological state, the more harmonious the interpersonal relationship, the higher the level of hope, and the better the quality of life. Hope is an important factor in coping with disease, and a key factor in maintaining a good psychological state and improving the quality of life of patients. At the same time, although the youth in the prime time of life, economic foundation, social and family marriage has not yet solid, for the study, work, marriage, career development, and other important responsibilities, and has been a source of stress that cancer, but they have a rational thinking on life, even experienced a severe stress events, still can be adjusted through the psychological and behavior to adapt to stress, hope for the future [17]. Therefore, we should encourage and guide patients to correctly understand the disease, the importance of maintaining a good psychological state. Wu Zijing et al. [18] believed that the level of hope can reduce the psychological stress of patients, relieve their pressure and pain in the treatment process, and improve their overall quality of life. At the same time, with the continuous progress of medical technology and the continuous emergence of new anticancer drugs, coupled with the universal benefit policy of medical insurance reform, most young and middle-aged cancer patients are full of hope for treatment.

To sum up, young cancer patients quality of life of affected by multiple factors of comprehensive medical staff in the clinical practice, we should pay more attention to this special group young cancer patients, understand their body-mind-club-spirit, to provide them with good social support and harmonious living environment, let the young cancer with good psychological state and social support, brave in the face of disease, overcome the disease. The limitation of this study is that due to the limitation of research time and funds, the sample size of this study is small, which needs to be further discussed in the future.

\section{References}

[1] Barr, R. D., Ferrari, A., Ries, L., et al. (2016). Cancer in Adolescents and Young Adults: A Narrative Review of the Current Status and a View of the Future [J]. JAMA Pediatr., 2016, 170(5): 495-501. DOI: 10.1001/jamaediatrics.2015.4689. $\square$

[2] Li Xue-yan. (2017). Surveillance results of the causes of death of residents in a county of Huizhou City, Guangdong Province from 2009 to 2015 [J]. Occupational Health, 2017, 33(8): 1090-1093.

[3] Shen Wenhao, Xie Haibin, Li Junqiang, et al. (2011). Analysis of the causes of death in Sihui city, Guangdong province during 2000-2010 [J]. South China Preventive Medicine, 2011, 37(6): 4246.

[4] Medicine, I. O. (2005). From cancer patient to cancer survivor: lost intransition [J]. Jpn J Exp So Psychol, 2005, 54(1): 55-67.

[5] Husson, O., Prins, J. B., Kaal, S. E., et al. Adolescent and young adult (AYA)lymphoma survivors report lower mphoma survivors report lower health-related quality of life compared to a normative population: results from the PRO-FILES registry [J].

[6] Zhang Fangyuan, Shen Aomei, Ma Tingting, et al. (2018). Clinical Practice Guidelines for Cancer Symptoms Management in China [J]. Nursing Research, 2018, 32(1): 8-12.

[7] Zhao Haiping, Wang Jian. (2000). Social support and hope in patients with hemodialysis [J]. Chinese Journal of Nursing, 2000, 35(5): 306-308.

[8] Chen Lulu, Peng Li, Tang Tang, et al. (2012). A study on the psychological resilience of patients with gynecological cancer [J]. Journal of the Third Military Medical University, 2012, 34(2): 137-140.

[9] Xiao Shuiyuan. (1994). Journal of Clinical Psychiatry, 1994(2): 98-100. (in Chinese with English abstract)

[10] Hu Yan, Ken Sellick. (2003). Anxiety, depression and quality of life tracking in patients with gastrointestinal malignance [J].Chinese Journal of Mental Health, 2003,17(12): 810-812.

[11] Hu Liping. (2009). Influence factors of quality of life in cancer patients and intervention measures [J]. Journal of Nursing, 2009, 24(3): 87-89.

[12] Liu Shaohua, Qiang Wanmin, Chen Yuhong, et al. (2015). Analysis of the quality of life of breast cancer patients during postoperative chemotherapy [J]. Journal of Nurse Education, 2015, 30(23): 2115-2118.

[13] Ke Qiujin. (2018). Effects of social support on negative emotion and quality of life in patients with cervical cancer [J]. Chinese Journal of Medical Innovation, 2018, 15(3): 83-86.

[14] Tang Lei, Qiang Wanmin, Wang Ying, et al. (2019). Study on the relationship between the quality of life of patients with cancer [J]. Journal of Nurse Development, 2019, 34(11): 985-987. 
[15] Chen Ling, Zhao Chunying, Li Yongtao, et al. (2012). Study on the marital quality of young breast cancer patients [J]. Nursing Research, 2012, 26(4): 1076-1078. DOI: 10.3969/j.issn.1009-6493.2012.012.009.

[16] Zhao, S. X., Qiang, W. M., Guo, F. L. (2019). The influence of family function on quality of life in young patients with advanced cancer [J]. Journal of Nursing Management, 2019, 2(19): 86-89.

[17] Long Jifang, Huang Xuqian, Zhou Na, et al. Current situation and influencing factors of hope level in 308 middle-aged patients with cancer [J]. Nursing, 2019, 26(8): 37-41. (in Chinese)

[18] Wu Zijing, Liu Ye, Li Xiaohan. (2018). The effect of hope level on psychological resilience and coping style in breast cancer patients [J]. Nursing Research, 2018, 32(7): 1038-1041. 